\title{
Spontaneous (primary) candida peritonitis
}

\author{
Joe SukHabote mD, Hugh J Freeman mD
}

\begin{abstract}
J SUKHABOTE, HJ FREEMAN. Spontaneous (primary) candida peritonitis. Can J Gastroenterol 1995;9(3):144-146. A 49-year-old female presented with abdominal pain and ascites. Subsequent investigations revealed Candida albicans in the ascitic fluid without evidence of systemic candidiasis or a source of local infection in another site. Additional studies revealed no evident underlying immunological disorder and the gastrointestinal tract was intact. Therapy with amphotericin B led to resolution of abdominal pain and ascites with no recurrence.
\end{abstract}

Key Words: Ascites, Bacterial peritonitis, Candida peritonitis, Immunosuppression, Primary peritonitis

\section{Péritonite à Candida spontanée (primaire)}

RÉSUMÉ : Une femme de 49 ans se présente pour douleur abdominale et ascite. Les épreuves diagnostiques révèlent la présence de Candida albicans dans le liquide d'ascite, sans signe de candidose systémique ni source d'infection locale provenant d'un autre foyer. Les épreuves additionnelles ne révèlent aucun signe de trouble immunologique sous-jacent et les voies digestives sont intactes. Le traitement par amphotéricine B a fait disparaître la douleur abdominale et l'ascite, sans récurrence.

SPONTANEOUS (PRIMARY) usually due to a bacterial agent, without a recognizable source of infection or inflammation. There is continuing debate as to the mechanism of organism entry into the peritoneal cavity, although the gastrointestinal tract is believed to be the likely source. Spontaneous bacterial peritonitis remains a very serious complicating clinical disorder in patients with chronic liver diseases, usually with ascites, and causes a high mortality rate.

Although the incidence of candida infections has increased, peritonitis due to candida infection is very uncommon (1). Candida albicans may cause massive ascites by direct peritoneal involvement. This usually occurs in patients with a pathological or artificial route of contamination, or their presence might result from an occult gastrointestinal perforation. The usual precipitating factors or associated clini-

Department of Medicine (Gastroenterology), University of British Columbia, Vancouver, British Columbia

Correspondence and reprints: Dr Hugh Freeman, ACU F-137, Vancouver Hospital (UBC Site), 2211 Wesbrook Mall, Vancouver, British Columbia V6T 1W5. Telephone (604) 822-7216

Received for publication June 13, 1994. Accepted October 17, 1994 cal conditions specifically associated with candida infection include perforated peptic ulcer disease, traumatic intestinal perforation, gastric and/or intestinal surgery and peritoneal dialysis.

In this report, a female patient is described with spontaneous or primary peritonitis and ascitic fluid that cultured Candida species. She responded completely to antifungal therapy using amphotericin B with complete resolution of abdominal pain and ascites.

\section{CASE PRESENTATION}

A 49-year-old woman initially presented in the emergency room with a two-month history of abdominal pain and fever. Approximately four months earlier she developed jaundice and was diagnosed with 'hepatitis', attributed to alcohol abuse. The jaundice subsequently resolved but she developed anorexia and increasing abdominal girth followed by the onset of diffuse and poorly localized abdominal pain with fever, chills and occasional night sweats. Before current hospitalization, she received treatment with spironolactone and amoxicillin.

Initial examination revealed temperature of $37.8^{\circ} \mathrm{C}$ and slight tachycardia of 104 beats/min. Ascites was evident with abdominal tenderness; rebound was present but there was no lymphadenopathy or peripheral stigmata of chronic liver disease.

Laboratory investigations revealed: hemoglobin $115 \mathrm{~g} / \mathrm{L}$; white blood cells 
$17.0 \times 10^{9} / \mathrm{L}$; and platelets $628 \times 10^{9} / \mathrm{L}$. Liver chemistry tests included: total bilirubin $16 \mu \mathrm{mol} / \mathrm{L}$ (normal 2 to 23 ); alkaline phosphatase $477 \mathrm{IU} / \mathrm{L}$ (normal 30 to 110); and aspartate aminotransferase $624 \mathrm{IU} / \mathrm{L}$ (normal 5 to 47). Serum amylase, glucose and immunoglobulins were normal. Serological studies for hepatitis A, B and C were negative. Paracentesis revealed yellow, cloudy fluid with 5000 red blood cells and 5000 white blood cells (24\% neutrophils, 32\% mononuclear cells, 44\% lymphocytes). Analysis of the ascitic fluid revealed total protein of $27 \mathrm{~g} / \mathrm{L}$. Gram stains of the fluid showed no organisms but peritoneal fluid cultures demonstrated C albicans. The patient was treated with intravenous amphotericin $\mathrm{B}$, and abdominal pain and ascites completely resolved.

Additional investigations to exclude other causes of infection as well as to locate the source of the candida including cultures of feces, sputum, skin, cervix, vagina, liver, cerebrospinal fluid, blood and bone marrow - were normal. Serological studies for human immunodeficiency virus, cytomegalovirus, Epstein-Barr virus, herpes simplex virus and fungi were negative. Radiographic examinations of the chest and abdomen, including barium contrast studies of the upper and lower gastrointestinal tracts, were normal as were ultrasound and computed tomography of the abdomen and pelvis (except for ascitic fluid). Fibreoptic endoscopic examinations of the upper gastrointestinal tract and colon, with biopsies of the esophagus, stomach, small and large intestine, were normal. Histological evaluation of the liver revealed nonspecific lobular hepatitis with some periportal fibrosis.

\section{DISCUSSION}

$\mathrm{C}$ albicans and other species of Candida are frequent ubiquitous microbiological agents on normal mucous membranes of the mouth, vagina and intestinal tract (2). Candida species have also been cultured from the feces in up to $31 \%$ of healthy subjects and in an even higher percentage of patients receiving broad-spectrum antibiotic treatment (3). If the organism becomes invasive it may result in a variety of acute or chronic, localized or widely disseminated lesions (1). Generally, C albicans is not pathogenic in healthy humans but it may become a virulent pathogen in immunosuppressed patients or those suffering from several metabolic or neoplastic disorders (eg, diabetes, malignant lymphoma), in whom it can complicate total parenteral nutrition or follow treatment with antibacterial or corticosteroid drugs $(1,4)$. Conversely, severe and very extensive candidiasis may result in a significant, but an entirely reversible, immunological impairment in white blood cell function, specifically, in neutrophil candidacidal activity; in a previous report (3), extensive esophageal candidiasis was described simulating changes in the acquired immunodeficiency syndrome. Although our patient had evidence of liver disease, possibly related to prior alcohol abuse, the ascites appeared to be due, at least in part, to infection with positive cultures of the peritoneal fluid for $\mathrm{C}$ albicans. After the patient was treated intravenously with a potent antifungal agent, amphotericin B, abdominal pain and ascites completely resolved.

C albicans peritonitis is most commonly seen as a complication of peritoneal dialysis, in perforation of an abdominal viscus or following gastrointestinal surgical procedures (3-6). To our knowledge it has not been recorded as a primary or spontaneous cause of peritonitis, even in patients with chronic liver disease and ascites. Candida species are frequently isolated from the peritoneal fluid of peritoneal dialysis patients, in whom the organism appears to be a contaminant and can cause clinically significant peritonitis as reflected by the presence and persistence of fever, peritoneal signs, peripheral leukocytosis, positive peritoneal cultures for candida and purulent ascitic fluid (3). C albicans peritonitis also occurs in $1 \%$ of renal transplant recipients; in these patients it is most often due to an unrecognized intestinal perforation or other intraperitoneal disease. The pathogenic role of $\mathrm{C}$ albicans peritonitis in patients with po- lymicrobial enteric flora is poorly understood. In surgical patients, candida has generally been isolated from those with a spontaneous perforation or a surgical opening in the gastrointestinal tract (6). It appears that isolation of Candida species has been most frequent from patients having surgical therapy for severe pancreatitis, recurrent perforation of the gastrointestinal tract or anastomotic leakage (6); moreover, for surgical patients, mortality was significantly greater in the presence of Candida species infections. Aggressive antifungal treatment has been recommended (3) because it appears to lower mortality.

In the absence of an obvious source of infection, fungal peritonitis, including $\mathrm{C}$ albicans peritonitis, appears to be exceedingly rare. A diabetic with renal failure and prolonged broad-spectrum antibiotic treatment complicated by fungal peritonitis has been recorded although the specific organism in this patient was not noted (7). Combination intraperitoneal and intravenous treatment with amphotericin B has been recommended (7) for fungal peritonitis although no studies to date have carefully explored an optimal treatment regimen for candida peritonitis.

A number of fungal organisms may rarely cause peritonitis, usually in the setting of an immunodeficiency state. These include peritoneal histoplasmosis (8), coccidioidomycosis (9) and disseminated cryptococcal infections (10). In some patients these may mimic neoplastic disease, be associated with disseminated granulomatous inflammatory disease or lead to a fatal outcome. Recognition of fungal agents, particularly $\mathrm{C}$ albicans, may be significantly improved if ascitic fluid is submitted in blood culture bottles. If $\mathrm{C}$ albicans is detected, treatment consists of a search for the infection source as well as intravenous antifungal treatment.

\section{REFERENCES}

1. Myerowitz RL, Pazir GJ, Allen CM. Disseminated candidiasis: changes in incidence, underlying diseases and pathology. Am J Clin Pathol 1977;68:29-38. 
2. Noble MA, Chan V, Mangal AK, Carter CJ, Whittaker JS, Freeman HJ. Candida esophagitis in a male homosexual with evidence of a serum-associated inhibitor of neutrophil candidacidal activity. A case of 'pseudo-AIDS'. Can J Gastroenterol 1987;1:33-5.

3. Bayer AS, Blumenkrantz MJ, Montgomerie JZ, Galpin JE, Coburn JW, Guze LG. Candida peritonitis. Report of 22 cases and review of the English literature. Am J Med 1976;61:832-40.

4. Reeves KO, Ripepi AC, Carter RE, Williams TW. Candida peritonitis in a quadriplegic. Treatment with amphotericin B. South Med J 1972;65:325-8

5. Solomkin JS, Flohr AB, Quie PG, Simmons RL. The role of Candida in intraperitoneal infections. Surgery 1980;88:524-30.

6. Calandra T, Bille J, Schneider R, Mosimann F, Francioli P. Clinical significance of candida isolated from peritoneum in surgical patients. Lancet 1989;ii:1437-9.

7. Runyon BA. Surgical peritonitis and other diseases of the peritoneum, mesentery, omentum, and diaphragm. In: Sleisenger MH, Fordtran J, eds.
Gastrointestinal Disease,

Pathophysiology, Diagnosis, Management, vol 2, 5th edn. Philadelphia: WB Saunders, Ltd, 1993:2004-14.

8. Reddy P, Gorelick DF, Brasher CA, Larsh H. Progressive disseminated histoplasmosis as seen in adults. Am J Med 1970;48:629-36.

9. Saw E, Shields SJ, Comer TP, Huntington RW. Granulomatous peritonitis due to cocidioides immitis. Arch Surg 1974;108:369-71.

10. Clift SA, Bradsher RW, Chan $\mathrm{CH}$. Peritonitis as an indicator of disseminated cryptococcal infection. Am J Gastroenterol 1982;77:922-4. 


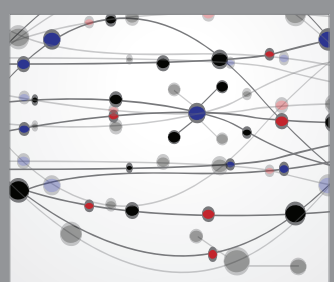

The Scientific World Journal
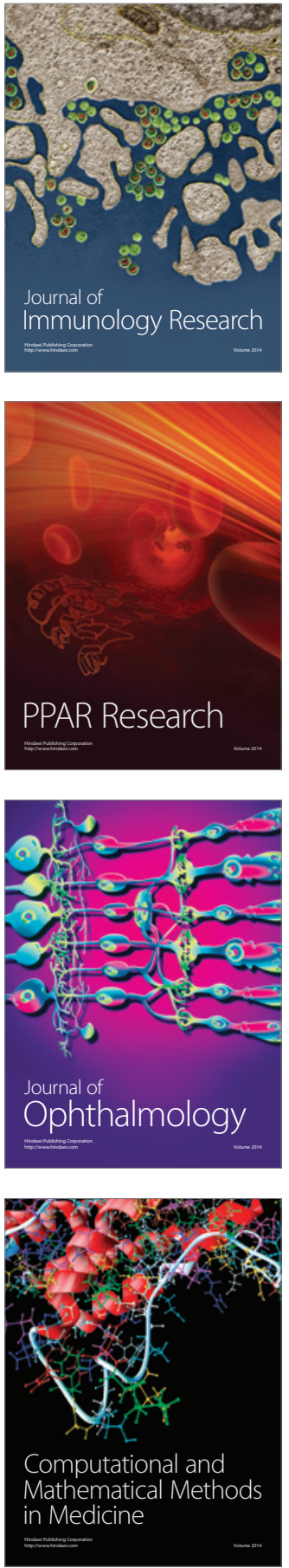

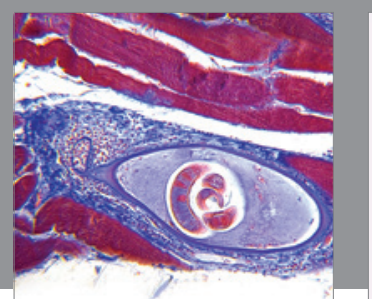

Gastroenterology Research and Practice

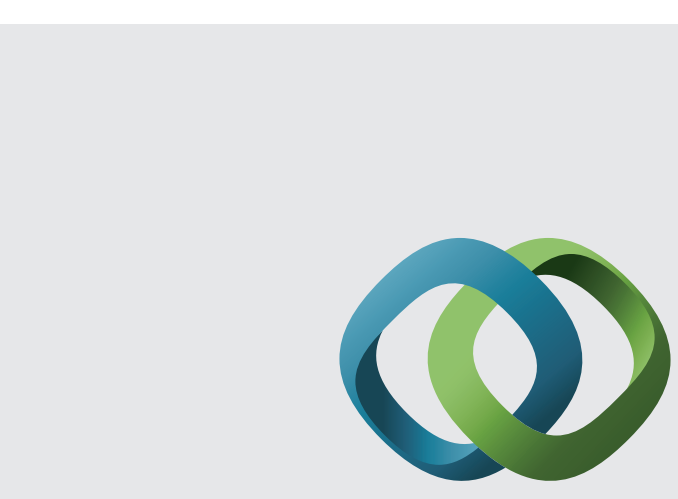

\section{Hindawi}

Submit your manuscripts at

http://www.hindawi.com
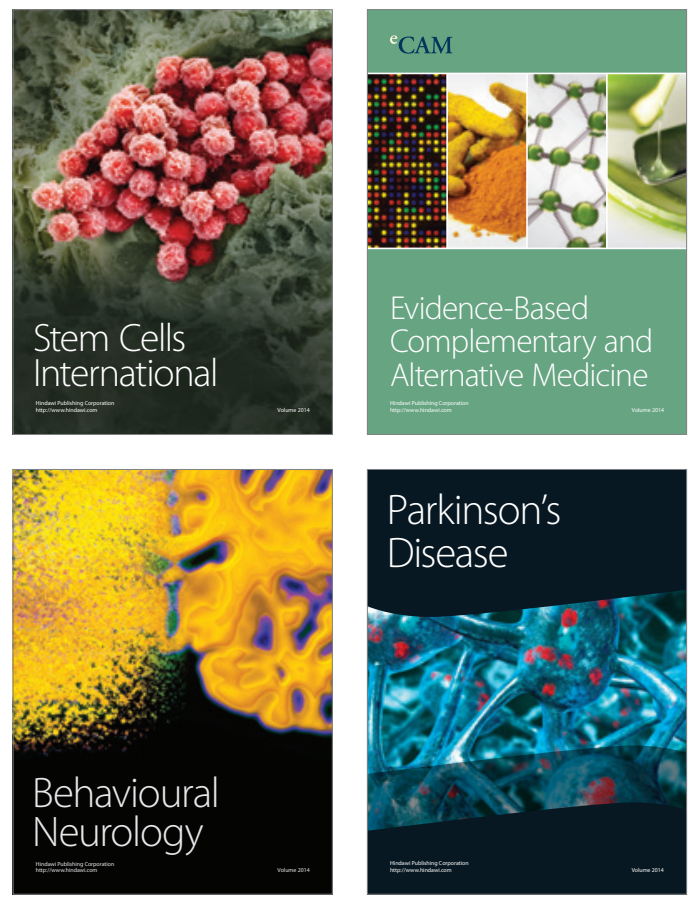
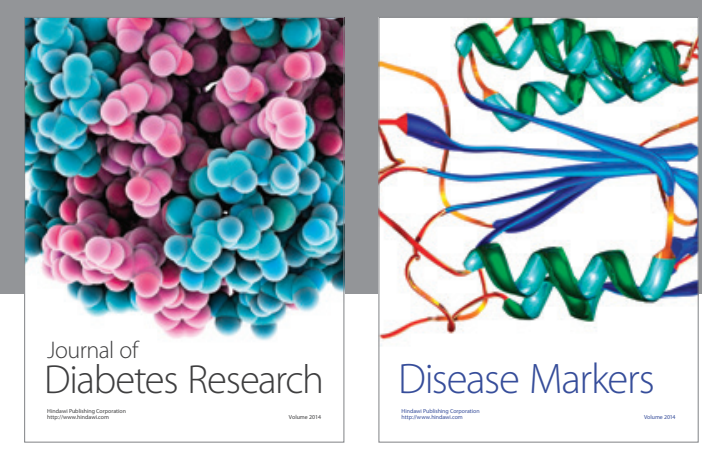

Disease Markers
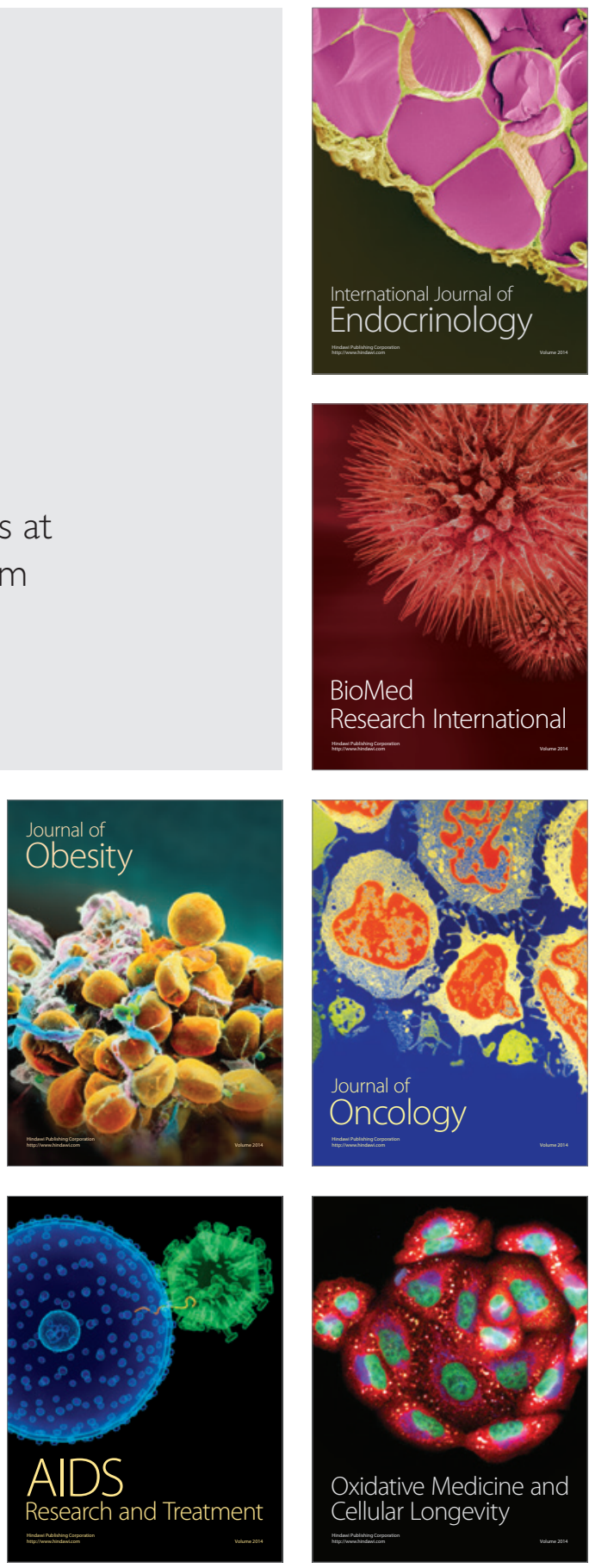